\title{
AS NOVAS DIRETRIZES DEFENSIVAS E 0 RECRUTAMENTO MILITAR. A CAPITANIA DE SÃO PAULO NA SEGUNDA METADE DO SÉCULO XVIII
}

\author{
Christiane Figueiredo Pagano de Mello \\ Universidade Federal de Ouro Preto*
}

\begin{abstract}
Resumo
Interessa-nos analisar neste artigo a resistência ao recrutamento militar como um conflito entre distintas concepções de poder e de espaço, isto é, entre as exigências centralizadoras apresentadas pelo governo central e seus representantes ultramarinos para a defesa da zona meridional da América portuguesa, e os interesses regionais presentes nas comunidades locais. Pretendemos, para tanto, dedicar a análise à Capitania de São Paulo, examinando os diversos conflitos, bem como as soluções encontradas por seus governadores, a fim de impor, ou negociar, diante das inúmeras dificuldades existentes, o recrutamento militar aos habitantes das comunidades locais.
\end{abstract}

Pallavras-Chave

Guerra $\bullet$ Deserção • Diretrizes Militares • Estratégias Locais

\section{Abstract}

It is our interest to analyze in this article the resistance to military recruitment as a conflict between different conceptions of power and space, that is, between the centralizing demands presented by the central government and its ultramarine representatives for the defense of the meridional zone of Portuguese America, and the regional interests present in the local communities. Within such mainframe, we intend to devote our analysis to the Capitany of Saint Paul, thus examining the diverse conflicts, as well as the solutions found by their governors, aiming at imposing or negotiating, in spite of countless difficulties, the military recruitment upon the inhabitants of the local communities.

\section{Keywords}

War $\bullet$ Desertion $\bullet$ Military Directives $\bullet$ Local Strategies

\footnotetext{
* Bolsa Recém-Doutor financiada pelo CNPq na Universidade Federal de Ouro Preto -UFOP. Doutora em História pela Universidade Federal Fluminense - UFF. Este artigo faz parte da minha tese de doutorado intitulada Os Corpos de Auxiliares e de Ordenanças na Segunda Metade do Século XVIII. As Capitanias do Rio de Janeiro, São Paulo e Minas Gerais e a Manutenção do Império Português no Centro-Sul da América, UFF, 2002, mimeo.
} 


\section{Introdução: A Guerra e as Novas Diretrizes Militares}

A segunda metade do século XVIII é um período especialmente interessante para o estudo das forças militares. Eram imperativas as necessidades de uma intensa reorganização militar, tanto no Reino de Portugal, como, também, no Estado do Brasil, sua principal terra colonial, onde se fazia indispensável aumentar a capacidade defensiva. Tais necessidades decorriam das crescentes tensões vividas na Europa, resultantes da celebração, em agosto de 1761, do Pacto de Família, em que os vários Bourbons então reinantes se comprometiam a defender mutuamente seus Estados.

Na ocasião, embora D. José fosse casado com uma princesa Bourbon, não podiam os pactuantes esperar que Portugal aderisse ao Pacto, aliado como era da Inglaterra, então adversária da França e da Espanha na chamada Guerra dos Sete Anos, luta armada que foi travada de 1756 até 1763.

Assim, a Coroa portuguesa, foi forçada a abandonar sua posição de neutralidade e a participar da fase final da Guerra dos Sete Anos. Após o estabelecimento dos Estados Ibéricos em campos opostos nesse conflito europeu, a contenda entre Portugal e Espanha logo se prolongaria avançando para as indefinidas regiões fronteiriças sulinas. Vale notar que, como observa o historiador Fernando Novais, "ao lado das zonas de tensão entre as potências dominantes em luta pela hegemonia, França e Inglaterra, entre os países coloniais ibéricos se vão formando ao mesmo tempo outras zonas de tensão (sobretudo a região platina). Os dois tipos de conflitos correm paralelos, e se inter-relacionam continuamente (...)"1.

No caso português, especificamente, o conflito com a Espanha pelos territórios às margens do rio Uruguai havia demonstrado claramente a precária capacidade de resistência de seu exército, sobretudo quando da invasão e conquista pelo governador de Buenos Aires, D. Pedro de Cevallos, da Colônia do Sacramento, em dezembro de 1762, bem como da vila do Rio Grande e da margem norte do canal que conectava a Lagoa dos Patos ao mar.

Não obstante assinado em fevereiro de 1763 o Tratado de Paz que havia de pôr termo à Guerra dos Sete Anos, restituindo a Portugal tudo o que fora ocupado pelos espanhóis, D. Pedro de Cevallos dispôs-se a devolver, dez meses

${ }^{1}$ NOVAIS, Fernando. Portugal e Brasil na Crise do Antigo Sistema Colonial (1777-1808). São Paulo: Hucitec, 1983, p. 51. 
após assinado o Tratado, apenas a Praça da Colônia, retendo o restante do território - as ilhas de São Gabriel, Martim Garcia e das Duas Irmãs e o Rio Grande de São Pedro com o seu território - e não permitindo à Colônia do Sacramento qualquer contato com o território contíguo.

Tensionavam-se, portanto, as questões da delimitação das fronteiras das possessões portuguesas ao sul da América; a perspectiva de guerra era flagrante, e notória a necessidade de reavaliar o sistema defensivo até então utilizado. Com o intuito de aumentar a capacidade defensiva portuguesa na América uma série de medidas foram implementadas. Podem-se citar, entre outras, a transferência, em 1763, da capital do Estado do Brasil para o Rio de Janeiro, mais próximo das regiões auríferas e mais apto a coordenar as ações militares que se prefiguravam ao Sul do Estado, o envio de regimentos militares portugueses para o Rio de Janeiro e posteriormente para o Sul.

A nova estrutura militar previa, e constantemente reiterava a todos os governadores da América portuguesa, a necessidade de cooperação entre as Capitanias do Estado do Brasil. Mereceram atenção, especialmente, as de São Paulo, Minas Gerais e Rio de Janeiro. A Coroa Portuguesa prescrevia como estratégia: “(...) que com a união de todos os trêz Governos, se possa consolidar huma força Superior(...)", e renovava: "He, porem, necessario, que sem a menor perda de tempo, se procure em todos os trêz Governos instruir as Milicias, nos Pontos essenciais de marcharem unidos"3.

No esquema estratégico-militar traçado e montado pela Coroa para a ofensiva no Prata, cada uma das três Capitanias teria uma função específica: a de São Paulo viria a "constituir um tampão defensivo entre a área hispano-americana e a região da mineração. Paralelamente cobriria a defesa da Capital recém-transferida." "; a de Minas Gerais deveria dispor de um corpo militar pronto para acudir aos domínios meridionais, bem como para marchar para a Capital do Rio de Janeiro em caso de necessidade. E à última caberia não só supervisionar toda a organização militar voltada para a defesa da região do Prata, como,

${ }^{2}$ Idem.

${ }^{3}$ Idem.

${ }^{4}$ BELLOTTO, Heloísa Liberalli. Autoridade e Conflito no Brasil Colonial: O Governo do Morgado de Mateus em São Paulo (1765-1775). São Paulo: Conselho Estadual de Artes e Ciências Humanas, 1979, p. 47. 
também, enviar suas tropas para aquela região, além de, ainda, acudir militarmente as outras duas capitanias, se necessário fosse.

A organização militar e a intensa militarização da população masculina da Colônia a ela inerente, impostas pelo governo de D. José I ao Estado do Brasil, representavam uma parte complementar das demais reformas implementadas "na realização concreta de todo um plano político-administrativo geral"s que tinha como meta a defesa do território, a expansão econômica e, sobretudo, o fortalecimento do poder central. No que concerne à política territorial, as medidas centralizadoras concretizaram-se sob o aspecto estratégico-militar da seguinte forma: "o problema da defesa perde o seu caráter local e se torna geral." . Assim sendo, em consonância com as demais diretrizes político-administrativas que o governo de D.José traçara para o Brasil, traduzidas pelo fortalecimento do poder central, pode-se constatar que, com relação à organização militar, a intenção régia pode ser definida, em termos gerais, da seguinte forma: "Não se tratava mais de organizar corpos militares locaes, com as suas leis próprias, como sucedia até então, sem a maior ligação entre si, sem um traço comum (....) mas sim, inspirada nos mesmos princípios e sob o mesmo comando. Não se tratava mais de um sentimento de defesa local dos governos das capitanias, criando suas guarnições, debaixo das impressões do momento, como sucedia no Rio, Bahia e Pernambuco. Tratava-se de organizar um exército debaixo das mesmas leis, da mesma direção e da mesma disciplina (....)"

\section{As Prescrições Centralizadoras e o Recrutamento militar}

Devido à política de intensa militarização da sociedade colonial imposta pelas Instruções e Cartas Régias durante a segunda metade do século XVIII, criaram-se incontáveis Corpos de Auxiliares, muitos dos quais deveriam par-

\footnotetext{
${ }^{5}$ MACHADO, Lourival Gomes. "Política e Administração sob os Últimos Vice-Reis." In: História Geral da Civilização Brasileira, Dir. Sérgio Buarque de Holanda, A Época Colonial, vol.2, Editora Difel, SP, 1960, p. 360.

${ }^{6}$ MACHADO, Lourival Gomes. "Política e Administração sob os Últimos Vice-Reis." In: História Geral da Civilização Brasileira, Dir. Sérgio Buarque de Holanda, A Época Colonial, vol.2, São Paulo: Editora Difel, 1960, p. 360.

${ }^{7}$ FREIRE, Felisbello. História da Cidade do Rio de Janeiro. Rio de Janeiro: Typ. Da Revista dos Tribunais, 1912., p. 705.
} 
ticipar, nas campanhas sulinas, ao lado da tropa regular. Pode-se verificar, contudo, que as ações de recrutamento constituíam momentos de enorme convulsão social: quando de seu início, dava-se, de imediato, a fuga dos elementos em risco de se verem integrados às fileiras. Além do mais, muitos daqueles que não conseguiam escapar ao aliciamento, acabavam por desertar.

Parece possível sintetizarem-se as motivações da grande repugnância da população colonial à sua militarização nas seguintes razões: a violência e vexação com que se recrutavam os combatentes, a falta de assistência pontual do soldo e pão prometidos, o mau tratamento recebido de seus governantes, o apego ao espaço original de socialização, isto é, a saudade da terra e dos parentes, bem como, e não menos relevante, o medo da guerra. Interessa-nos, contudo, analisar a resistência à mobilização militar como um conflito entre distintas concepções de poder e de espaço, isto é, entre as exigências centralizadoras apresentadas pelo governo central e seus representantes ultramarinos para a defesa da zona meridional da América portuguesa, e os interesses corporativos $^{8}$ e regionais presentes na comunidade local. Pretendemos, para tanto, dedicar a análise à Capitania de São Paulo, examinando os diversos conflitos, bem como as soluções encontradas por seus governadores, a fim de impor, ou negociar, diante das inúmeras dificuldades existentes, o recrutamento militar aos habitantes das comunidades locais.

Assim sendo, perante a imposição do recrutamento militar, as comunidades locais responderam com a fuga, e muitos daqueles que não conseguiram escapar, desertavam. À debandada dos habitantes de suas habitações para aquelas regiões mais distantes, os "Mattos" ou "Certoens", o então Capitão-General de São

\footnotetext{
${ }^{8}$ A dimensão corporativa, fornecida pela concepção e prática organicista, ou, daí, corporativa, do poder político, caracterizava a estrutura social do Antigo Regime, em que o poder régio se distribuía, originariamente, pelos centros de poder local existentes em cada comunidade. Tais centros constituíam-se nos principais agentes responsáveis pelos seus ordenamentos político-administrativos. Um dos princípios orientadores da prática política do Estado Absolutista português, até meados dos setecentos, postulava a delegação de poderes militares, administrativos e políticos, isto é, o respeito pela 'autonomia' da jurisdição dos centros de poder constitutivos das comunidade locais, sob a condição de que estivessem harmonizados com as diretrizes da cabeça do corpo político do Estado, o Rei, como um dos fundamentos sobre os quais repousava uma sociedade bem governada. Em resumo, havia-se que compatibilizar as jurisdições locais, respeitadas suas particularidades, poderes e direitos, com a jurisdição real. Ver: HESPANHA, António Manuel. Poder e Instituições na Europa do Antigo Regime. Lisboa: Fundação Calustre Gulbenkian, 1982.
} 
Paulo, Martim Lopes Lobo de Saldanha (1775-1782), por sua vez, respondia "pela multidão de prizões, que tenho feito de malfeitores, sem que tenhão parte, onde possão estar seguros". Diante de tamanha diligência, segundo o Governador, “(...) sahiram dos Mattos muitas famílias, que ao tempo de se levantarem as tropas, se tinhão refugiado nelles com seus filhos, vindo-se me offerecer para Soldado, e pedindo perdão da sua inobediência (...)". Reiterando sua prática, afirma categoricamente "que nenhum Certão, por maior que fosse, lhe serviria de azilo." E conclui que o maior objetivo de seu Governo "(...) he de que esta Capitania viva na mais cega obediência ao Seu Soberano, e com o maior respeito as Suas Justiças (...)"9.

Entretanto, havia, na época, outras formas de se fugir às fileiras, algumas, inclusive, pelas vias legais, através dos privilégios. Outras formas havia, não menos eficientes como, por exemplo, a prática do suborno. Desta, relata-nos André Ribeiro Coutinho, uma vez comandante de um dos Regimentos do Rio de Janeiro, em seu livro Capitão de Infantaria Portuguez, que inclui um extenso capítulo relativo ao recrutamento. Adverte o autor àquele que se inicia na função de Capitão: "Muito cuidado se deve ter em que os crimes mais ordinários desta diligencia, são o aceitar peitas das partes, por lhes escuzarem seus filhos"10.

Outro ponto importante, que o experiente Capitão chama a atenção, é sobre o cuidado com as redes de fuga e de deserção que se formavam e constantemente atuavam constituindo-se em "Huma das cousas, que mais perturba, embaraça, e toma tempo nas facturas [recrutamento], e reconduções [dos desertores] são Frades, Clerigos, Conventos, e Casas de pessoas poderosas (...)"11.

O que se nos impõe destacar, neste momento, com relação ao recrutamento e suas resistências, sejam elas por suborno, utilização de privilégios, fugas ou deserções e suas redes de proteção, é a forte presença de uma sociedade organizada de acordo com uma lógica fundamentalmente local, isto é, corporativa, resistente, senão impermeável, a determinadas pressões do centro. A partir dessa perspectiva, o recrutamento era visto pela comunidade local como uma interferência externa, que desarticulava e mesmo arruinava sua estrutura interna.

\footnotetext{
9 "Carta de Martim Lopes Lobo para Matinho de Mello e Castro, 17/2/1777”, AHU, SP, Avulsos, Cx.31, doc. 2751.

${ }^{10}$ COUTINHO, André Ribeiro. Capitão de Infantaria Portuguez. Lisboa: Na Regia Officina SYILVIANA, 1751, p.173.

${ }^{11}$ Idem, p. 181.
} 
Mesmo diante da eminência de uma guerra e, portanto, da necessidade de remessa de tropas destinadas à proteção da área fronteiriça em litígio, motivos bastante prementes devido aos quais o poder central é levado a fazer tais interferências, a comunidade local não os reconhece como inerentemente seus, posto que seu espaço social de referência é a esfera local - espaço político-geográfico constituído por uma comunidade -, não coincidente, portanto, com a totalidade da extensão territorial da América portuguesa, isto é, o espaço físico de exercício da soberania do monarca em sua Colônia.

De acordo com Enrinque Peregalli “os recrutamentos despertaram na população paulista uma animosidade crescente. Resistências que espalhavamse pelos quatro cantos da capitania. Não foram sublevações, revoluções ou movimentos de massas e não apresentavam uma organização específica. As mais prolongadas giraram em torno das Câmaras" ${ }^{\prime 2}$. Através dos Requerimentos e Representações feitos por diversas Câmaras ao Rei D.José, podemos reiteradamente constatar a forte presença desta lógica local ou corporativista e, portanto, de resistência ao recrutamento de homens para fora de suas comunidades de origem. Em outros termos, podemos claramente perceber a resistência da comunidade, que se expressa indignada através das Câmaras. Senão, vejamos:

Pelo Requerimento dos oficiais da Câmara da vila de S.Sebastião da comarca de São Paulo a D.José I, no ano de 1756: “(...) por se lhe tirar quase todos os annos os f ${ }^{\text {os }}$ dos mesmos moradores $\mathrm{p}^{\text {a }}$ soldados por ordem do Gov. ${ }^{\text {or }}$ da Praça de Santos por cuja razão vai a d. ${ }^{a} \mathrm{~V}$. ${ }^{\mathrm{a}} \mathrm{em}$ hua geral decadencia acrescendo tambem a falta para cultivarem a terra por q' alem de faltarem os q' assentam Praça os mais se auzentão com o urror de q' lhes suceda o mesmo (...)"13.

Também a Representação da Câmara da vila de Santa Ana de Moji das Cruzes, no ano de 1777: “(...) o continuo pranto com que lamentão suas mulheres e Filhos e na mizéria q’ experimentão nas abzencias dos Pais e maridos por andarem estes efetivamente empregados no Serviço de V.Mag. ${ }^{\text {de }}$, huns no Continente do Rio Grande e outros nas fortalezas da praça de Santos, como Sold. ${ }^{\text {ss }}$ Auxiliares (...)"14.

\footnotetext{
${ }^{12}$ PEREGALLI, Enrique. Recrutamento Militar no Brasil Colonial. Campinas: Editora da UNICAMP, 1986, p. 122.

13 "Requerimento dos oficiais da Câmara da vila de S. Sebastião da comarca de São Paulo a D.José, 13/1/1756”, AHU, SP, Avulsos, Cx.21, doc.2062.

14 “Representação dos oficiais da Câmara da vila de Santa Ana de Moji das Cruzes, 3/7/ 1777”, AHU, SP, Avulsos, Cx.31, doc.2763.
} 
Constam das cartas enviadas à Coroa, pelo Governador e Capitão-General de São Paulo, Morgado de Mateus (1765 e 1775), inúmeras referências às dificuldades que encontrava em levantar os Corpos de Auxiliares, destinados, muitos deles, aos combates nos domínios sulinos, por exemplo: “(...) p. ${ }^{\text {la }}$ repugnancia com q' os Povos fogem de ser soldados (...)"15; “(...) aborrecem elles todos naturalmente o nome de Soldados”16 “(...) os accidentes que havia premeditado de levantes, deserçoens, resistencias (...)"17, e etc.

\section{A Reformulação das funções militares das Tropas de Auxiliares}

Em vista das crescentes tensões locais provocadas pelo recrutamento de soldados, sugere, engenhosamente, Morgado de Mateus à Coroa, alterações com relação às funções militares dos Regimentos de Auxiliares. No ano de 1774, a Coroa acata suas observações e considera: “(...) visto serem os ditos Regimentos na maior parte formados das Principais Cabeças das Famílias; e de Homens cazados, e estabelecidos: Sendo certo que esta qualidade de tropa só he boa, e util para se empregar no proprio Paiz, guarnecendo os Portos e lugares; mas tão bem as suas cazas e Familias que é o maior estimulo, para se comportarem como devem: E nesta consideração ordena Sua Magestade, que os referidos Corpos sejam unicamente destinados a este Serviço"18.

A reformulação das funções militares dos Auxiliares é o reconhecimento explícito, pelo poder central, do predomínio cultural de cunho corporativo das comunidades locais na constituição daqueles Corpos. Em outros termos, passase a admitir que sua mobilização só seria desencadeada adequadamente aos interesses da Monarquia Absoluta, não por intermédio de uma ordem geral, referida à defesa da longínquas regiões em seu extremo sul, mas, sim, a nível da esfera local e regional, seu "maior estimulo".

\footnotetext{
${ }^{15}$ Oficio de D.Luiz Antonio de Souza Mourão para o Conde de Oeiras, 4/11/1765" AHU, SP, Avulsos, Cx.24, doc.2265.

16 "Ofício n. ${ }^{\circ}$ terceiro do Governador Morgado de Mateus para o Conde de Oeiras, 31/7/ 1765”, AHU, SP, Avulsos, Cx.23, doc.2237.

17 “Oficio de D.Luiz Antonio de Souza Mourão (Morgado de Mateus) para o Martinho de Mello e Castro, 30/3/1775” AHU, SP, Avulsos, Cx.30, doc.2696.

18 "Carta de Martinho de Mello e Castro para Dom Luiz, Antonio de Souza Mourão, 22/4/ 1774”, AHU, SP, Códice 569, p.66.
} 
Ao transferir o governo de São Paulo, em 1775, a Martim Lopes Lobo, Morgado de Mateus deixa a seu sucessor um conjunto de Instruções, contendo 40 ítens, tendo por fim informá-lo sobre os assuntos pertinentes àquela Capitania. No item de número 20, inicia seus comentários sobre as questões militares, mais especificamente com os Auxiliares. Neste item, ao descrever a forma pela qual se organizam as Tropas Auxiliares, torna ainda mais explícita a sua lógica corporativa ou localista: “(...) cuja consistencia se funda em os Privilegios, que Sua Magestade lhe mandou conceder, elles servem de paga; como tambem na arrumação, em que se achão em cada huma das villas, a donde cada Companhia tem os seus officiais competentes que a conservão, e a governão, o que não succederia assim, se os Soldados fossem recrutados de deferentes partes; e este particular Governo de cada companhia he sufficiente para as conservar (...)"19.

Não obstante a Ordem Régia de 1774, que reservava aos Auxiliares a exclusiva missão de proteger os portos e lugares da Capitania, estes, ainda assim, sempre que as autoridades o julgavam necessário, continuaram sendo solicitados para as campanhas ao sul do Estado.

Ora, devemos considerar que, mediante o agravamento das tensões nas fronteiras ao sul da América, provenientes, na época, das ofensivas espanholas de Vertis e Salcedo, a partir de 1774, e, posteriormente, da de Cevallos, em 1777, e dos longos períodos de batalhas delas decorrentes, seria militarmente insustentável, do ponto de vista da Coroa, manter os Auxiliares exclusivamente destinados à defesa de suas respectivas Capitanias. Nesse sentido, cumpre lembrar, ainda, que as determinações da Carta Régia de 24 de janeiro de $1775^{20}$, acima analisada, prescreviam o envio de socorro da Capitania de São Paulo para os domínios meridionais da América e, de Minas Gerais, para a defesa da cidade do Rio de Janeiro, capital do Vice-Reino.

Desse modo, pode-se constatar que o Vice-Rei Marquês do Lavradio, a quem cabia, segundo as mesmas determinações, a supervisão geral de toda a ação militar direcionada ao sul, fizera, então, solicitações aos Capitães-Generais

19 “Intruções de D. Luiz Antonio de Souza para Martim Lopes Lobo de Saldanha, SP, 25/ 6/1775”, BNL, Reservados, Códice 4530.

20 “Oficio de Martinho de Mello e Castro para o Marquês do Lavradio, 24/1/1775", AHU, SP, Avulsos, Cx 30, doc 2688. 
dos Corpos de Auxiliares de ambas as Capitanias, tanto para a defesa do Rio de Janeiro, como para a das praças do sul. Senão, vejamos: em carta de 20 de agosto de 1775, dirigida ao Marquês de Pombal, informava o Vice-Rei que "Eu escrevo ao Gen. al de Minas para que me mande dous ou trez terços de Aux. ${ }^{\text {es } " 21}$; ao mesmo Capitão-General de Minas Gerais, em carta de 2 de julho de 1776, determinava: “(...) porém como esta gente só não bastará no cazo de eu effetivam. ${ }^{\text {te }}$ ser attacado, hé sem duvida que as forças com q' El Rei Meu Sr. determina eu seja auxeliado com os Corpos Auxr. ${ }^{\text {es }}$ dessa Cap. ${ }^{\text {nia }}$ que V.Ex. ${ }^{\text {a }}$ avizou estarem formados (....)"22.

E, no que se refere à Capitania de São Paulo, pode-se verificar o mesmo procedimento, sendo que o destino dos Corpos de Auxiliares eram as fronteiras sulinas Assim, em carta de 11 de abril de 1777 ao seu Capitão-General, estabelecia o Vice-Rei: “E pello q' pertence aos Corpos Auxiliares, julgo q' estes devem hir marchando sem perda nenhu 'a de tp. ${ }^{\circ}$, bem entendido, q' dadas as providencias, p. ${ }^{a}$ elles serem socorridos nas suas marchas, assim como tambem todas as mais

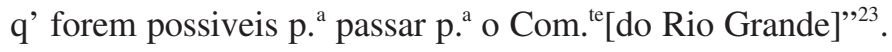

Muito embora os Auxiliares permanecessem com a primordial tarefa de defesa de suas respectivas Capitanias, protegendo seus portos, ou os lugares onde residissem, do perigo maior de invasões estrangeiras, cabe destacar, entretanto que, em ocasiões de urgência militar, a Coroa detinha a prerrogativa de revogar os privilégios concedidos. Assim sendo, diante da necessidade de defesa de sua Colônia, tornava-se imperativo que a Coroa, mesmo que provisoriamente, revogasse a exclusividade concedida aos Auxiliares, fazendo com que viessem, também, a atuar como força e reforço na defesa das regiões em litígio ao sul da América portuguesa.

21 "Carta do Marquês do Lavradio para o Marquês de Pombal, RJ, 20/8/1775”, BNL, Reservados, Códice 10624, s/p.

22 “Carta n $n^{\circ}$ 4, Carta do Marquês Vice-Rei do Estado, RJ, 2/7/1776", BNRJ, Obras Raras, Antonio de Noronha, Cartas, Livro 1 - Correspondências Passivas - Minas Gerais, 17761779, p.48 - 50.

23 "Carta do Marquês do Lavradio para o Governador da Capitania de São Paulo, RJ,11/ 4/1777’, BNL, Reservados, Códice 10624, s/p. 


\section{As Concepções do Espaço Político-Territorial}

Diante das questões acima levantadas, partimos da premissa de que a organização social e política da Colônia, no nível local, permanece enquadrada nos padrões de uma concepção organicista ou corporativa da sociedade, segundo a qual a sensação de pertença de seus habitantes era dada a partir da esfera local, de sua comunidade, reconhecendo-se, a partir daí, sua hierarquia, também local, onde o Rei representava seu tomo máximo, a cabeça. Dinâmica política essencialmente localista, donde "a dispersão do poder por uma multiplicidade de células sociais, cada qual relativamente autonoma em relação ao poder da coroa e cuja unidade interna é mantida pela ligação dos seus membros ao chefe local por laços políticos particulares" ${ }^{24}$. Dessa forma, os habitantes coloniais se sentiam parte do Império português, posto que assim o Império era concebido de acordo com a lógica corporativista.

Vale destacar, ainda, que sua concepção de unidade decorre, portanto, da agregação destes espaços político-administrativos, as comunidades locais, sem contudo, perderem neste processo, seus particularismos e suas relativas autonomias. Símbolo maior da unidade, o Rei atua como um poder de controle e harmonização do exercício destes poderes inferiores. Sendo assim, a concepção política corporativista da Monarquia portuguesa investe o espaço local e regional de um significado primordial e essencial do seu sistema de poder.

O que nos impõe destacar no momento é a presença de duas dimensões diversas do entendimento do espaço político-territorial coexistindo na mesma realidade temporal, quais sejam: a corporativa, como analisado acima e predominante na organização da sociedade colonial, e a voluntarista que se 'impõe' a partir da segunda metade do século XVIII, sendo esta concepção e prática do poder e da sociedade representadas na Colônia pelos Vice-Reis e Governadores-Generais através das determinações e instruções enviadas pela Coroa portuguesa que deveriam executar nos domínios americanos.

Estratégias diversas de apreensão e controle do território, portanto, decorrem das duas diferentes dimensões político-geográficas acima mencionadas. Na estratégia corporativa, a organização do espaço político

${ }^{24}$ HESPANHA, António M. Poder e Instituição..., op. cit. p.35. 
estabelece-se a partir de uma "estrutura granular" ${ }^{25}$, isto é, a fragmentação do poder pelos diversos centros político-territorias, as comunidades locais, como meio melhor de defesa e administração. A estratégia voluntarista concebe a organização político-administrativa do espaço como uma "estrutura contínua", considerando, portanto, condição necessária para a boa administração e defesa territorial uma ordem baseada em um poder único, que se imponha sobre as relações comunitárias e acima das diferenças regionais.

Duas diferentes concepções que, se inseridas nas necessidades práticas da efetivação de planos e interesses, estarão sujeitas a inúmeros confrontos entre si, bem como, serão compelidas a negociarem na busca de possíveis consonâncias. Assim, temos a estratégia corporativa, consubstanciada política e territorialmente nas comunidades locais e, portanto, orientada no sentido de defender os interesses regionais ou locais: uma organização espacial baseada em uma "estrutura granular", e a "estratégia voluntarista ou centralizadora", visando dissolver, sujeitar e integrar tais circunscrições político-territoriais dentro da órbita de um mesmo e único centro político ${ }^{26}$, assim convertendo a anterior granularidade em uma "estrutura contínua".

Dessa forma, segundo Hespanha para a estratégia voluntarista ou centralizadora “(...) o regionalismo é visto como uma tendência que leva a periferização, a desunificação e a miniaturização do espaço, é comparado ao egoísmo particular (portanto, numa flagrante violação do princípio fundamental da prevalência do interesse público sobre o privado), sendo ainda, considerado como persistência das classificações politico-geográficas passadas, e identificado como um sinal de atraso e de emergência de uma mentalidade pré-racional" ${ }^{27}$.

Nesse sentido, o intento do poder central em concentrar em si todo o poder político direcionar-se-á no sentido de tentar diluir as influências não-centrais, isto é, regionais e locais, processo esse que, se transposto para a efetivação prática da política centralista, estará sujeito a incessantes conflitos entre as dis-

\footnotetext{
${ }^{25}$ As expressões “estrutura granular" e "estrutura contínua”, referentes à organização do espaço, foram citadas por Diogo Ramada Curto em O Discurso Político em Portugal (1600-1650). Lisboa: Universidade Aberta, 1988, p.179.

${ }^{26}$ HESPANHA, António M.. L'Espace Politique dans L'Ancien Régime, Coimbra, Separata do número especial do Boletim da Faculdade de Direito de Coimbra, 1983, p.22-44.

${ }^{27}$ HESPANHA, António M.. L’Espace Politique..., op.cit., p.23.
} 
tintas concepções de poder e de espaço, colocando em xeque, dessa forma, as questões da eficácia real do poder absoluto e centralizador, bem como suas pretensões teóricas de onipotência.

É a partir das contradições geradas no interior deste processo que se deve sublinhar a resistência colocada pela vila de Ubatuba ao poder central, representado pelo então Capitão-General de São Paulo, Lopes Lobo de Saldanha, que da seguinte forma transcreve a conduta de seus habitantes: “(...) ameaçando, e prendendo os Oficiaes, a quem incumbo as dilligencias (...) e andarem dizendo atrevidamente, que eu em S.Paulo, e elles em Ubatuba, continuando os mesmos dispotismo, que em todos os tempos praticarão de fazerem ineficazes as ordens dos superiores, e inda as de S.Mag. ${ }^{\text {e }}$, dando azillo a outros criminosos, e Dezertores, chegando ao Excesso de os irem frequentemenente buscar à Capital do Estado (...)"28.

É, portanto, o não reconhecimento dos moradores da vila àquela forma de poder que pressupõe uma subordinação direta ao Capitão-General, projeção de um poder único e não partilhado. Em outros termos, é o baluarte corporativo, sobretudo no seu significado regionalista, que resiste, ativando e afirmando os fenômenos sociais centrífugos que percorrem o interior da sociedade e do exército - as deserções -, a fim de recuperar seu espaço e seu poder originários, desejando destituir seu usurpador e delimitando seu espaço como político, quando afirmam: "eu em S.Paulo, e elles em Ubatuba".

28 "Portaria de Martim Lopes Lobo de Saldanha para o tenenete de Cavalaria Auxiliar Manuel Francisco de Toledo, 17/1/1776”, AHU, SP, Avulsos, Cx.31, doc.2719.

29 “Carta de Martim Lopes Lobo para Matinho de Mello e Castro, 17/2/1777”, AHU, SP, Avulsos, Cx.31, doc.2751.

30 "Portaria de Martim Lopes Lobo de Saldanha para o tenenete de Cavalaria Auxiliar Manuel Francisco de Toledo, 17/1/1776", AHU, SP, Avulsos, Cx.31, doc.2719.

${ }^{31}$ Conduta semelhante tiveram o Juiz Ordinário e o Capitão-Mor da vila da Ilha Grande, no Rio de Janeiro, em 5/11/1771, ao não reconhecerem as ordens do Vice-Rei, Marquês do Lavradio, o qual escreve indignado: "Sendo me prezente que passando o Escrivão, e Alcaide de Paraty, a essa Villa p. . prenderem de Ordem minha a Jozé Apolinario, o não poderão conseguir, tanto por Vm. ${ }^{\mathrm{ce}}$ [juiz ordinário] o apoiar, como pelo Capitão Mor querer prender aos ditos Officiaes, sabendo elles hião a esta delig. ${ }^{a}, \mathrm{Vm} .{ }^{\mathrm{ce}}$ junto com o mesmo Cap. ${ }^{\mathrm{am}}$ Mor, prenderão Logo ao referido Jozé Apolinario, e ambos pessoalm. ${ }^{\text {te }}$ nesta Cid. e.", ANRJ, Correspondências dos Vice-Reis com diversas Autoridades, Códice 70, vol.7, p.11. 
A fim de absorver os particularismos locais, e converter os moradores da vila em vassalos obedientes e submissos ao único e supremo poder do Rei, o Capitão-General de São Paulo, que tinha por objetivo maior de seu governo “(...) que esta Capitania viva na mais cega obediência ao Seu Soberano, e com o maior respeito as Suas Justiças (...)"29 , determina, então, ao tenente da cavalaria Auxiliar da vila de Guaratinguetá a diligência de prender os "ditos criminosos e insolentes" ${ }^{30}$ e trazê-los à sua presença ${ }^{31}$.

Dessa forma, na composição do espaço de estrutura contínua ou centralizado "a integração de cada parcela acarreta sua alienação política e a sua inclusão na órbita de um centro político situado fora dela (...) as unidades tradicionais não constituem mais peças autônomas, mas, sim 'partes", que deverão estar submetidas ao comando do único centro político, a $\mathrm{Coroa}^{32}$.

\section{Estratégias diversas de defesa militar}

Obviamente que diferentes concepções e práticas político-territoriais resultam em diversas formas e estratégias de defesa militar. Veja-se que, em uma organização espacial-política de estrutura granular corporativa, composta pelos vários e dispersos pólos político-administrativos, com suas particularidades, jurisdições e relativa autonomia, a defesa territorial se organizará fundamentalmente a partir das estratégias locais de combate, isto é, da pequena guerra de emboscadas, assaltos noturnos, surpresas, incêndios e devastações. Nesse contexto, as tropas militares eram organizadas em função dos perigos e ameaças que se apresentassem, desfazendo-se quando de sua cessação. Constituíam-se, ainda, as tropas militares, essencialmente, em forças locais que, além da falta de articulação interna e de saberes técnicos, não tinham qualquer ligação entre si, não dispondo, portanto, de um traço, uma tática em comum pela qual pudessem orientar suas ações durante um combate, resultando daí a dificuldade em manter uma disciplina no campo de batalha e em fazer com que a tropa cumprisse as ordens de combate, donde, portanto, "cada combatente ou grupo de combatentes, movia-se de acordo com objetivos - por vezes apenas determinados pela perspectiva do saque - que ele próprio escolhia. Nesse contexto, o chefe militar apenas podia dar ordens muito gerais, acudindo com os seus

\footnotetext{
${ }^{32}$ HESPANHA, António M.. L'Espace Politique..., op.cit., p.27-54.
} 
homens de confiança aos pontos mais difíceis, deixando para o final do embate, se vitorioso, a complicada tarefa de voltar a reunir a massa já sem norte" ${ }^{33}$.

Já consoante a uma concepção político-territorial voluntarista, em que se percebe a organização do espaço como uma "estrutura contínua" e global, sob o comando da Coroa como seu único centro político, comando esse irradiado para a Colônia através de seus representantes ultramarinos, formula-se, necessariamente, uma diversa estrutura militar de defesa para a Colônia.

Primeiramente, consideremos as determinações régias no concernente às Capitanias do Rio de Janeiro, São Paulo e Minas Gerais. Cada uma delas, embora administrativamente independente, era concebida como parte de uma engrenagem político-territorial maior: o Centro-Sul da América portuguesa. Sua articulação com a mesma deveria se concertar de modo absolutamente preciso. Dentro de um determinado plano militar maior em cuja defesa territorial estava inserida, as ordens e diretrizes militares criteriosamente definidas pelo poder central determinavam a cada Capitão-General, e ao Vice-Rei, a funcionalidade específica da Capitania que governava.

Atendo-nos mais especificamente à atividade militar, concebe-se, ainda, neste período, que a eficiência na defesa territorial decorre fundamentalmente de dois fatores primordiais: das forças militares (número de efetivos) e de sua devida regularização técnica. Em outros termos, no que respeita ao recrutamento militar, ocorrerá uma substancial intensificação de contingentes, visando propiciar uma maior quantidade de tropas aptas ao front de batalha. No que se refere à tática militar, a organização das forças deveria estar baseada em regras únicas e estáveis. Buscando uma uniformidade militar e uma unidade de ação bélica, impunha-se aos soldados estarem devidamente habituados ao manejo das armas, à ordem imposta pelas formações táticas e, nelas, à manutenção de suas posições, e, sobretudo, a uma completa subordinação às ordens de seus superiores.

Tais preocupações são constatáveis através das recorrentes ordens régias dirigidas à Colônia determinando aos Capitães-Generais e ao Vice-Rei a perfeita manutenção das Tropas de Auxiliares e das pagas de suas respectivas Capitanias: que se apresentassem bem reguladas, disciplinadas e, portanto, devidamente aptas para o combate. Com idêntica preocupação de regulação das tropas colo-

${ }^{33}$ BEBIANO, Rui. "Elementos de um Barroco Militar", Revista de Histórias das Idéias, Universidade de Coimbra, N. ${ }^{\circ}$ 11, 1989, p.117. 
niais fora enviado, ainda, no ano de 1767, o Tenente-General João Henrique Böhm, responsável pela aplicação dos regulamentos do Conde Lippe, referentes à organização, à estratégia, à tática, à disciplina, etc.

De fato, algumas providências tinham sido tomadas pela Coroa no sentido de melhorar e regular a defesa de sua Colônia, seja por meio do envio de oficiais para reorganizarem suas tropas, seja através de reforços constituídos por tropas pagas vindas do reino. Entretanto, as múltiplas demandas das tropas terrestres, em muito ultrapassavam as possibilidades da Coroa de supri-las, tanto com armamentos quanto com soldos. Assim sendo, vale lembrar que, nesse contexto de precariedade, bem como da urgência bélica que se fazia na zona meridional da América, tornou-se estrategicamente indispensável o aproveitamento das estratégias locais dos soldados-aventureiros da Capitania de São Paulo, paralelamente, e não obstante as mesmas prescrições régias que determinavam a regularização e a disciplinarização militar das tropas coloniais como fatores imprescindíveis para a eficaz defesa de sua Colônia.

\section{Recrutamento e o Confronto com as Estratégias locais}

No que concerne à Colônia, a fim de dar cumprimento às diretrizes régias de reformulação militar das forças das Capitanias, o Vice-Rei e os CapitãesGenerais deparavam-se não somente com as dificuldades provenientes da Coroa, como também com as decorrentes das resistências locais, o que tornava a tarefa destes representantes ultramarinos imensamente delicada. Senão, vejamos: estando o Sul da América na eminência de um conflito bélico, o que, portanto, implicaria, de acordo com as diretrizes régias, em acionar uma estratégia em que os Corpos militares estivessem tecnicamente disponíveis para "marcharem unidos", isto é, uniformizados e predispostos a uma mobilidade que abarcasse grandes distâncias de suas comunidades de origem, tal situação nos remete a algumas considerações:

Se, por um lado, fica-nos evidente que o Vice-Rei e os Capitães-Generais das Capitanias, enquanto representantes daquele poder central tinham plena noção da necessidade de intensa mobilização militar de substanciais contingentes populacionais de suas Capitanias, com a finalidade de defesa e socorro das regiões sulinas, não é evidente, entretanto, senão pelo contrário, que tais forças se deixem mobilizar em função de objetivos militares fora da sua região. Sua presença no plano local não é imediatamente transponível para uma esfera de ação em escala maior, ou para um local a elas estranho. É preciso notar que a possibilidade de 
investir essas forças em outras regiões demandaria tempo, posto que implicaria em todo um processo de absorção de uma outra forma de poder, agora situado no exterior da comunidade local, bem como de uma disciplina militar a elas estranha.

Outro ponto faz-se, ainda, necessário explicitar: note-se que, desde sua fundação no ano de 1679, estendendo-se ao longo da centúria seguinte, já eram freqüentes os deslocamentos de tropas em direção ao Sul para a defesa da Colônia do Sacramento, com o fito de restituir, ou manter, a defesa daquela praça contra as recorrentes investidas espanholas. Ora, tais deslocamentos foram inegavelmente marcados pela resistência da população, traduzida tanto pelas fugas ao recrutamento como pelas constantes deserções. O que nos impõe destacar é que, em decorrência da forte inflexão quantitativa e qualitativa da nova estratégia militar, imposta durante a segunda metade do século XVIII, a resistência popular virá a se acentuar, atingindo seu ápice em decorrência da intensificação do recrutamento, bem como da exigência de uma maior regulação e disciplinarização das tropas coloniais. Analisaremos, ainda, mais adiante, como a própria organização político-territorial corporativa também virá a se constituir em empecilho para a implementação dessas novas diretrizes.

Assim, vejamos: o Capitão-General da Capitania de São Paulo, Morgado de Mateus, referindo-se às dificuldades que costumava encontrar ao levantar as Companhias de Auxiliares, remete-nos a um descompasso daqueles povos com relação às demandas das novas diretrizes defensivas, apontando, ainda, para o profundo estranhamento que provocava, nestes povos, as intensas mobilizações militares: “(...) e que nunca tinha visto similhante factura de Soldados (...)" ${ }^{\prime 3}$; “(...) por q' alem de não estar isto aqui em pratica e ser $p .{ }^{\text {a }}$ estes homens hua couza nova e estranha (...)"35.

O descompasso intensifica-se, ainda, quando, face às exigências militares impostas pelo poder central, as 'milícias', cujo dever seria encontrarem-se enquadradas em uma determinada ordem e disciplina, reduzindo a uma uniformidade os particularismos locais, os povos, conforme constata Morgado de Mateus, respondem a respeito dos Auxiliares: “(...) aborrecem elles todo o

34 “Oficio de D.Luís Antonio de Sousa para o Martinho de Mello e Castro, 30/3/1775", AHU, SP, Avulsos, Cx.30, doc. 2696.

35 “Ofício n. ${ }^{\circ}$ terceiro do Governador Morgado de Mateus para o Conde de Oeiras, 31/7/ 1765”, AHU, SP, Avulsos, Cx.23, doc.2237. 
emprego q' os prive daquela liberdade e preguiça em q' estão criados (...)"36. Ora, ao lhes serem impostas uma ordem e uma disciplina que lhes são exteriores, além de colidirem com o seu modo de organização local, ficam incapacitados de prontamente responder àquelas demandas militares, para eles absolutamente estranhas, além de distantes e incongruentes com sua lógica interna.

Dessa forma, também, não é de se estranhar que, seis anos após a promulgação do Regulamento do Conde Lippe e que deveria ser utilizado como modelo para o governo das tropas na Colônia, escrevia Morgado de Mateus que as forças de sua Capitania eram regidas por "hum misto entre o moderno e o antigo, sem haver couza determinada" ${ }^{37}$. Em 1766, ordena o mesmo Governador de São Paulo, que as tropas Auxiliares deveriam ser observadas "somente naquilo que for aplicável ao uzo desta America conforme a observância que se pratica na Capital do Rio de Janeiro" 38 . Ora, no Rio de Janeiro, de acordo com o Relatório do Marquês do Lavradio a seu sucessor, afirma ele que alterou algumas das medidas do General Böhn, que "pôs em pratica a execução do regulamento ainda em muitas daquelas coisas, que aliás não são praticadas neste pais, pelos prejuizos graves que geralmente se podem seguir, assim à vida dos homens como do Estado" 39 .

Em carta de 1776, do Vice-Rei Marquês do Lavradio a Lopes Lobo de Saldanha, o então novo Governador de São Paulo, ao fazer um balanço da situação das tropas, o Vice-Rei, comparando as pagas com aquelas que não recebiam soldo, acaba por tornar explícitos os limites da prática política centralista (uniformidade e disciplina) no que concerne aos planos de organização militar da Colônia. Afirma o Vice-Rei: "Se huns Corpos, que VEx. a formou com tanta atividade, cuidado, e despeza; compostos de Soldados, e Officiaes, que muitos já servião, e que a todos El Rei paga; que para estes Corpos eu concorri com tudo quanto pude; estes mesmos não pode VEx. ${ }^{a}$ conseguir ve los com uniformidade, nem em hum sofrivel estado de disciplina; que sucederá

\footnotetext{
${ }^{36}$ Idem.

37 “Carta de D.Luís Antonio de Sousa para o Conde de Azambuja, 27/6/1767”, DIHSP, vol. XIX, p.372, apud LEONZO, p.48.

38 “Ordem de D.Luís Antonio de Sousa sobre as obrigações que devem ter os oficiais e soldados das Tropas Auxiliares desta Capitania, 20/7/1766”, DIHSP, vol. LXV, p.135136, apud LEONZO, p.48.

${ }^{39}$ ARMITAGE, João. História do Brasil. Rio de Janeiro: Zélio Valverde, 1943, p. 216.
} 
a huns Corpos formados por gentes, que não são daquella profissão, que vivem muito distantes da presença de VEx. ${ }^{a}$, e que não tem ainda Officiais capazes, que possão instruir?" 40 .

\section{Recrutamento e o Espaço Tradicional}

O novo sistema de poder político e territorial depara-se, ainda, com outros e sérios obstáculos à efetivação de seus planos centralizadores, quais sejam aqueles derivados do modelo de organização política do espaço corporativista. Caracterizado pela sua descontinuidade geográfica e constituído de pequenas dimensões, o espaço tradicional corporativista é o espaço das pequenas comunidades, dotado de uma vida econômica e social comum.

Notam-se, portanto, as dificuldades práticas, no plano territorial, de se levarem a bom termo as diretrizes militares da Metrópole, no que concerne à composição dos corpos militares. Veja-se o que observa Morgado de Mateus: "Ha também outra dificuldade não pequena, e he as grandes distancias em que estão as Villas e Lugares huns dos outros havendo $\mathrm{m}$. ${ }^{\text {to }}$ poucos em q' se pode formar hua companhia inteira (...)"41 . Já em outra carta, enfatiza ainda mais as dificuldades provenientes do reduzido número de habitantes que compõem as comunidades locais: "Ao mesmo passo considero em levantar os terços de Auxiliares; e me parece que só em São Paulo poderei formar terços inteiros, por q' nesta Villa e nas mais destas Capitania não pode haver se não Companhias Soltas; por q' o pequeno numero dos seus habitantes não permite mais, como se ve das listas da Ordenanças que já tenho, e assim me afirmão que se fas em Minas”42.

Além de tais dificuldades, como observa Nanci Leonzo, "o temor aos recrutamentos para as constantes expedições de exploração e defesa do território ainda mais dispersaram a população, esvaziando as povoações, desagregando e mutilando famílias inteiras (...)"43

\footnotetext{
40 "Carta do Marquês do Lavradio para Martim Lopes Lobo, 7/8/1776", AHU, RJ, Avulsos, Cx.109, doc. 75 .

41 "Ofício n. ${ }^{\circ}$ terceiro do Governador Morgado de Mateus para o Conde de Oeiras, 31/7/ 1765 ", op.cit.

42 "Ofício n. ${ }^{\circ}$ quinto do Governador Morgado de Mateus para o Conde de Oeiras, 15/9/ 1765”, AHU, SP, Avulsos, Cx.23, doc.2256.

${ }^{43}$ LEONZO, Nanci. Defesa Militar e Controle Social na Capitania de São Paulo: As Milícias. Tese de doutoramento, USP, 1979, (mimeo), p.15.
} 
Os limites da atuação da Coroa, bem como da capital do Estado do Brasil, revelam outras facetas, não menos prejudiciais aos seus planos militares, especialmente quando a tais limites pode-se imputar a responsabilidade de promover as deserções e fugas ao serviço militar, que, deve-se anotar, eram freqüentemente combatidas com todo o vigor pelas autoridades coloniais e metropolitanas ${ }^{44}$. Tais limites dizem respeito ao seu aspecto financeiro, de fundamental importância, sobretudo em se tratando das Tropas de Auxiliares ${ }^{45}$.

Reconhecendo tais limites e suas inevitáveis conseqüências, além de nos revelar, também, a condição do soldado colonial do Estado absolutista português, considera o Vice-Rei, Marquês do Lavradio, ao Marquês de Pombal, a respeito dos Auxiliares: "eu estou já em grande dívida com estes povos, e como elles não tem de que vivão, que do seu trabalho, e o fruto das Suas terras, e dos generos, com que comercião, faltando-lhes o prompto pagamento, todos se escondem, e os que se sugeitão, hé com tal violencia, que reputão o que se

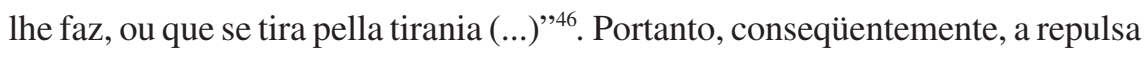
de ser soldado se justifica na própria condição do soldado, qual seja:"(...) a nudez do Soldado, a falta de pagamento e andarem estes Mendigando, motivos q' horrorizão aos Povos a Vida Melitar (...)", denuncia a Câmara da Cidade de São Paulo a D.José I ${ }^{47}$.

\section{Recurso às Estratégias Locais.}

Em 1775, à época da nomeação de D.Antonio de Noronha para CapitãoGeneral da Capitania de Minas Gerais, e de Martim Lopes Lobo de Saldanha para a de São Paulo, a Coroa expediu novas diretrizes defensivas para os do-

\footnotetext{
${ }^{44} \mathrm{O}$ artigo 14 do capítulo XXVI do "Regulamento para o exercício, e disciplina dos Regimentos de Infantaria dos Exércitos de Sua Magestade Fidelissima" organizado pelo conde Lippe, em 1763, prescreve enforcamento para o desertor em tempo de guerra e condenação a trabalhos forçados nas fortificações em tempo de paz", op.cit.

${ }^{45}$ Convém lembrar que as tropas de Auxiliares eram compostas por homens casados e chefes de família que, em ocasião de guerra, quando requisitados para guarnecer as fortalezas, engrossar as fileiras dos corpos militares estacionados na marinha, estes o faziam mediante soldo, de acordo com as disposições da Carta Régia que instituiu em Portugal, os Corpos de Auxiliares. 46 "Carta do Marquês do Lavradio para o Marquês de Pombal, 31/10/1776", AHU, RJ, Avulsos, Cx.110, doc.34.

47 “'Carta da Câmara da Cidade de São Paulo, 27/12/1775”, BNL, Reservados, códice 4530, p.192.
} 
mínios meridionais da América portuguesa. Visando direcionar ainda mais sua estratégia militar naquela região, delega às Capitanias do centro-sul, - Minas Gerais, São Paulo e Rio de Janeiro -, o encargo maior da responsabilidade na defesa e no socorro das fronteiras sulinas. Nesse contexto e momento, constituíam-se aquelas capitanias no centro político-administrativo e militar do Império português na América, devendo, portanto, seu objetivo ser único, consonante e uníssono. Assim, determina Martinho de Mello e Castro ao Vice-Rei que, "alem da cauza commum, que Sua Mag. e tem mandado estabelecer em todas as Capitanias (...)", se forme um "Plano Militar, por meio do qual, tenha V.Ex..": Em São Paulo hum prompto Socorro, para acudir aos Dominios Meridionais da America Portuguesa: E Em Minas Gerais hum Corpo de rezerva, também prompto, para se servir delle, e o fazer marchar, quando lhe for necessario, em deffença dessa Capital" ${ }^{\text {48 }}$. Determina, ainda, ao Vice-Rei, que os dois Governadores-Generais devem mantê-lo informado de tudo o quanto fazem ${ }^{49}$, para que, “no caso, em q' a guerra, que hoje ameaça tão somente o Rio Grande, Viamão,

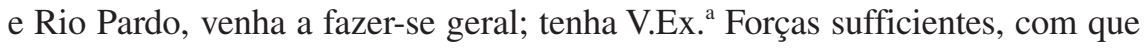
preserve e deffenda essa Capital de todo e qualquer Insulto"50.

Se a situação da capital, segundo o Vice-Rei, era já bastante precária no que concerne à sua defesa, não menos difíceis eram as circunstâncias da Capitania de São Paulo, constituída por uns povos que “(...) lhe custa infinitam..$^{\text {te }}$ o obedecerem (...) e se retiram para os Certoens Logo que se não convem no que elles querem" "51. Já quanto à de Minas Gerais, "Aq. ${ }^{\text {la }}$ Cap. ${ }^{\text {nia }}$ nunca foi Militar, ignorasse nella, tudo o q' hé Serviço Regular." 52 , e, quando chegam suas tropas

48 "Oficio de Martinho de Mello e Castro para o Marquês do Lavradio, 24/1/1775", AHU, SP, Avulsos, Cx 30, doc 2688.

${ }^{49}$ Segundo ALDEN, Dauril. Royal Government..., op. cit., p.447, "In critical times, such as the mid-seventies, the Crown did grant the viceroy exceptional war power and placed certain captains-general under their orders". Para um aprofundamento sobre a questão dos limites territoriais da autoridade do Vice-Rei, bem como as específicas relações que se estabeleciam entre este e os Governadores, e com os Capitães-Generais no Estado do Brasil, ver capítulo XVI, "Relation with Governors and Captains-General", p.447 a 471.

50 “Oficio de Martinho de Mello e Castro para o Marquês do Lavradio, 24/1/1775”, AHU, SP, Avulsos, Cx 30, doc 2688.

51 "Carta do Marquês do Lavradio para Matim Lopes Lobo de Saldanha, 7/8/1776", AHU, RJ, Avulsos, Cx 109 doc 75.

52 “Carta do Marquês do Lavradio para Matim Lopes Lobo de Saldanha, 22/5/1777”, BNL, Reservados, cod. 10631, s/paginação. 
à capital "cauzão motivo de rizo as suas figuras, e ainda de alguns as Suas Idades, por não serem ja competentes" 53 .

Por outro lado, imediatamente após chegarem as tropas pagas da Capitania de São Paulo ao Rio Grande de São Pedro, o general João Henrique Böhn envia ao Governador-General daquela Capitania uma carta contendo inúmeras críticas e reprovações a seu deplorável estado. Senão, vejamos: os "Oficiais são todos novos, não tem os precisos conhecim. ${ }^{\text {tos }}$ Militares" ${ }^{\text {"54 }}$, além de não encontrar a tropa "provida do preciso" 55 , chegava a afirmar, inclusive, que, com a mesma, "não se pode contar como tropa" 56 .

“Aflito”, escreve Lopes Lobo, Capitão-General de São Paulo, ao Vice-Rei, solicitando-lhe a necessária ajuda, a fim de que "fiquem satisfeitas aquellas irregularidades, com que se acha naquelle Continente a tropa dessa Capitania"57. Ao que não se dá por achado o Marquês em sua resposta: "V.Ex. a apromptou, como lhe permitiu o pouco tempo, e os poucos meios, que tem essa Capitania", alongando-se, ainda, a considerar "(...) que a V.Ex. ${ }^{\text {a }}$ se faria impossivel, e a mim, o remediar-mos em hum instante o descuido de tantos annos" ${ }^{\$ 5}$.

Bem sabia o Marquês, porém, que as tais irregularidades, encontradas nas Tropas acima referidas e por ele mesmo atribuídas não só ao fator tempo, mas, também, aos "poucos meios" disponíveis para colocá-las "provida(s) do preciso", não se deviam exclusivamente às insuficiências "que tem essa Capitania" de São Paulo, mas, resultavam, primordialmente, da falta de recursos da própria Coroa para devidamente equipar suas Tropas ultramarinas de armamentos, pólvora, uniformes e, sobretudo, pagamentos. Assim sendo, tais deficiências não se verificavam apenas na Capitania de São Paulo, mas, também, em todo seu domínio americano. Tampouco atingiam somente a tropa regular, que, a princípio e minimamente, deveria estar provida de oficiais "com conhecimentos

\footnotetext{
53 “Carta do Marquês do Lavradio para o Marquês de Pombal, 6/7/1775”, BNL, Reservados, cod. 10624, p.76.

54 "Carta do Marquês do Lavradio para Matim Lopes Lobo de Saldanha, 7/8/1776", AHU, SP, Avulsos, Cx 108, doc 51.

55 "Carta do Marquês do Lavradio para o Marquês de Pombal, 30/12/1776”, AHU, SP, Avulsos, Cx 108, doc 51.

56 “Carta do Marquês do Lavradio para Matim Lopes Lobo de Saldanha, 7/8/1776”, op.cit.

${ }^{57}$ Idem

${ }^{58}$ Idem.
} 
do Serviço, que deve fazer huma tropa semelhante (...)"59, mas, também, como acima explicitado, se alastravam pela Tropa de Auxiliares. Tais ocorrências se repetiam recorrentemente, a despeito do fato de as diretrizes militares determinadas pela Coroa prescreverem, continuamente, a necessidade de regularização e disciplinarização das Tropas coloniais. Tomemos, por exemplo, a Ordem Régia, emitida em 1771 para o Vice-Rei Marquês do Lavradio, acerca da importância das Tropas de Auxiliares: “o importantíssimo, e utilíssimo objeto dos Corpos Auxiliares; que a Exemplo de todas as Nações do Mundo, que tem Colonia, são a base fundamental, e a mais sólida forsa de cada hua dellas: O mesmo S. ${ }^{\text {nor }}$ espera que V.Ex. a tenha aplicado com o maior cuidado em formar, consolidar, e disciplinar os referidos Corpos; tendo a certeza que daqui se hade cooperar com tudo quanto for preciso para os fazer uteis ao Serviço e defença dessa Capitania" ${ }^{60}$. A real indisponibilização, por parte da Coroa, de suficiente e adequado armamento para tais corpos militares, ou, tampouco, de qualquer garantia de respeito ao devido soldo, quando de seu necessário deslocamento para a fronteira, transformava a urgente necessidade de "formar, consolidar e disciplinar" novos contingentes militares em objetivos praticamente inalcançáveis.

Mediante a falta de recursos Reais para arcar devidamente com sua colaboração na constituição das tropas na América, a fim de torná-las, de fato, úteis ao Real serviço, tornava-se imperativo o reconhecimento, pela Coroa, da necessidade de recorrer intensamente às estratégias e aos processos de combate locais como elementos imprescindíveis, porque, definidores, na guerra travada com a Espanha pela disputa dos territórios ao sul da América. Nesse sentido, reveste-se de interesse a avaliação que fizera o Marquês do Lavradio, em carta-resposta ao general João Henrique Böhm por seu espanto e reprovações feitas com relação às tropas de São Paulo chegadas ao Rio Grande de São Pedro. Esforçava-se o Vice-Rei em demonstrar ao general Böhm as vantagens que poderiam advir da utilização de tropas daquela qualidade. Para tanto, primeiramente, remete-se às guerras efetuadas na Europa, cujas tropas encontravam-se bem municiadas e submetidas a uma ordem e a uma regra. Considera, entretanto, seu aspecto contraproducente, visto que "o modo de se sustentarem hé todo o mesmo; e finalmente não tem vantagens huas sobre as outras" ${ }^{\prime \prime 1}$.

\footnotetext{
${ }^{59}$ Idem.

60 "Martinho de Mello e Castro para o Marquês do Lavradio, 1/10/1771", AHU, RJ, Avulsos, Cx.101, Doc. 54.

61 “Carta do Marquês do Lavradio para João Henrique Böhn, RJ, 10/2/1777”, BNL, Reservados, Códice 10631, s/ paginação.
} 
Nestes termos, ressalta o Marquês o caráter extremamente positivo que poderia haver na utilização de uma espécie de tropa que, embora mal equipada e mal regulada, em termos europeus, trazia em si a compensação e a vantagem de dispor de meios de combate que, por muito próprios, eram completamente inesperados e desconhecidos de seus inimigos: "todo o seu cuidado hé em fazerem hostilidades, sem se exporem, vivem nos mattos, sem fazerem diferença dos bichos, conhecem tambem, e acham-se familiarizados com aquelas habitações, que nelas se recolhem, ali se sustentam e conservão sem outro nenhum socorro, e dali saem como feras a fazerem estragos que em todos os tempos temos visto" ${ }^{62}$. Apostando, ainda, no diferencial como fator estrategicamente importante, quiçá o único recurso de que realmente dispunham os portugueses para enfrentar a guerra com os espanhóis, afirma o Marquês que, mesmo que tais extravagantes contingentes tivessem que enfrentar as "tropas ligeiras européias, que poderão fazer cá com estes bichos; hé sem dúvida que couza alguma, por que a tropa ligeira se não embrenha por mattos, se não a queles que conheçe (...)"63. Dessa forma, é possível verificar-se a especial atenção da Coroa, direcionada por seus representantes ultramarinos, para o máximo aproveitamento desse tipo de tropa, existente na Capitania de São Paulo e destinada às campanhas ao Sul do América, e composta, invariavelmente, de sertanistas e caçadores, quer fosse ela denominada de aventureiros, de caçadores ou de voluntários.

E como destaca Pedro Puntoni, os paulistas "particularizavam-se, desde o final do século XVI, por possuir um estilo militar perfeitamente adaptado às condições ecológicas do sertão. (...) Tinham uma dinâmica e um modo de operação ajustados para seus intentos de penetração nos sertões em busca do provável mineral precioso ou do infalível cativo indígena. Sabiam manejar a situação de carência alimentar e eram destros para a navegação nos matos fechados, nos cerrados ou caatingas" ${ }^{64}$.

A tempo, convém lembrar que a força terrestre, no Estado do Brasil, estava organizada em três escalões, a saber: O Exército de Linha, ou Tropa Paga,

\footnotetext{
${ }^{62}$ Idem.

${ }^{63}$ Idem.

${ }^{64}$ PUNTONI, Pedro. "A arte da guerra no Brasil: tecnologia e estratégia militares na expansão da fronteira da América portuguesa (1550-1700)", In Nova História Militar Brasileira. Rio de Janeiro: Editora FGV, 2004, p. 57 e 58.
} 
recrutado entre os solteiros; as Forças Auxiliares, constituídas por homens válidos, geralmente casados; e, finalmente, as Ordenanças, compostas pelos restantes homens militarmente úteis. Fora deste esquema, e para determinadas missões específicas, eram contratadas, mediante a promessa de soldo, companhias de aventureiros, caçadores ou voluntários.

\section{Recurso às Estratégias Locais: As Companhias de Aventureiros-Paulistas}

Morgado de Mateus, logo após sua chegada em Santos, para dar início ao governo de São Paulo, recebera ordens do Vice-Rei Conde da Cunha para levantar quatro companhias de Aventureiros naquela Capitania. Já ciente da sua situação militar, considerava o então governador que "Os ditos aventureiros fazem despeza m. ${ }^{\text {to }}$ gr. ${ }^{\text {de }}$ e não he tropa capaz de fazer seviço regular" ${ }^{\prime \prime 5}$; recebera, no entanto, as devidas informações acerca dos relevantes motivos existentes para se acionar esse tipo de tropa: "he a tropa mais util e mais propria q' pode haver para as campanhas de Rio Grande, adonde, se abrir a guerra são indispensavelmente necessarios pela quallidade de ataques e estratagemas com q' ofendem o inimigo, e por isso se fazem m. ${ }^{\text {to }}$ temidos. ${ }^{.66}$

Em 1766, mediante a notícia de " $\mathrm{q}$ ' os castelhanos crescião em numero naquela fronteira" ${ }^{\prime \prime}$, as quatro companhias paulistas de Aventureiros, formadas por Morgado de Mateus, foram, pela primeira vez, enviadas para as fronteiras do Sul. Contudo, não sem grandes dificuldades conseguiu o Morgado realizar sua expedição. Seu principal obstáculo remontava ao passado desta tropa, bem como às pendências financeiras desrespeitadas desde então ${ }^{68}$ : "as avoltadas pro-

\footnotetext{
65 “Oficio de Morgado de Mateus para o Conde de Oeiras, S.P., 4/8/1765”, AHU, SP., Avulsos, Cx. 23, doc. 2239.

${ }^{66}$ Idem.

67 "Oficio de Morgado de Mateus para o Conde de Oeiras, S.P. 9/3/1766", AHU, SP., Avulsos, Cx. 24, doc. 2294.

${ }^{68}$ Esse passado remonta à época do Tratado de Madrid, em 1750, que, temporariamente, definiu a soberania das Coroas de Espanha e Portugal na região meridional da América, estipulando, fundamentalmente, a troca da Colônia do Sacramento que estava em poder dos portugueses pela região dos Sete Povos das Missões Orientais então pertencente à Espanha. A fim de implementar o acordo de fronteiras, Gomes Freire fora nomeado plenipotenciário lusitano. Das Instruções que dera a Cristóvão Pereira de Abreu - comandante de grupos de aventureiros -, Gomes Freire afirmava que só poderia "fazer a dita demarcação e divisão" com "pessoas práticas, inteligentes e cientes na forma de viver em sertão e em descobertas". Referia-se ele aos
} 
meças de acrescentamento de soldos, e ajudas de custo, com q' esta qualidade de Tropa fora instituida no seu principio, a qual sendo só destinada para abrir os mattos; passou depois pello tempo em diante a regolar-se como milicia, ficando deste modo, com huns soldos tão desmedidos q' por essa cauza ninguém se atreveo athé o prezente, a lhes mandar pagar"69. Em consulta com o ViceRei Conde da Cunha acordaram, finalmente, o soldo devido a esta tropa, a fim de que fosse imediatamente enviada para as fronteiras sulinas, a despeito das apreensões geradas acerca da reação dos paulistas: "o melhor meio hera procurar a todo o risco ajusta-los desta vez por hum soldo, q' não excedesse, aos do Rio de Janeiro"70.

À medida em que as tensões se acirravam na América meridional com a conquista pelos espanhóis da Ilha de Santa Catarina, aumentavam as expectativas com relação aos paulistas. O Vice-Rei, em carta ao governador de São Paulo, considerava conveniente, a fim de atiçar o ímpeto paulista "e se renovarem no seu coração aq ${ }^{\text {le }}$ rancor q' em outro tp. ${ }^{o}$ tinhão aos Cast. ${ }^{0 \text { " } " 71}$, que soubessem “q' os Cast. ${ }^{\text {os }}$ dizem q' os seus dezejos mais ardentes, são de se vingarem dos paulistas (...) q' ainda q' lhes prometão trata-los com carid. ${ }^{\mathrm{e}}$, que a todos os que lhe cahirem nas mãos, elles hão-de tirar a vida com a maior tirania"72.

\footnotetext{
'bandeirantes' os “especialistas no sertão”, conforme classificação de Gomes Freire. ["Instruções de Gomes Freire de Andrade para o coronel Cristóvão Pereira de Abreu”, Anais da BNRJ 1928, vol.50, Apud, GOLIN, Tau. A Guerra Guaranítica, Op. cit., p. 247]

Em 1752, ordenou Gomes Freire a Cristóvão Pereira que fosse "as comarcas de São Paulo e Pernaguá" a fim de "formar uma tropa de 200 homens, em que entrem pessoas capazes de se oporem aos tapes [índios], caso seja preciso embaraçar-lhes alguma cilada (...)". Que estes homens fossem "cientes no viajar e cortar o sertão, sabendo caçar e pescar para a subsistência". Contratando essa tropa paulista para as fronteiras meridionais prometia-se aos soldados-aventureiros o salário de 4.800 réis, o qual não fora saldado. [Idem.]

Deve-se lembrar que os paulistas já tinham uma longa experiência naquela região, bem como com os indígenas que ali habitavam. A começar pelo ano de 1636, quando as reduções jesuíticas localizadas no alto Uruguai receberam o primeiro ataque da bandeira paulista de Raposo Tavares - da qual também participou Fernão Dias Paes - inaugurando um ciclo de escravidão e morte daqueles indígenas reduzidos. [GOLIN, Tau. A Guerra Guaranítica, Op. cit., p. 286]

${ }^{69}$ Idem.

${ }^{70}$ Idem.

71 “'Carta do Marquês do Lavradio para o Governador de São Paulo, RJ, 11/4/1777”, BNL, Reservados, Códice 10631.

72 "Carta do Marquês do Lavradio para Martim Lopez Lobo de Saldanha, RJ, 26/3/1777”, BNL, Reservados, Códice 10631.
} 
Em 11 de abril de 1777, em outra carta dirigida a Martim Lopez Lobo de Saldanha, lamenta o Marquês do Lavradio o acontecido na Ilha de Santa Catarina e informa, ainda, ao governador, das providências que se fazem necessárias "a fim de ivitar-mos a continuação de tão desgrasados sucessos"73. Tal derrota colocava em grave perigo não somente os domínios portugueses na América meridional, mas, sobretudo, segundo o Vice-Rei, se as forças inimigas se expandissem e conquistassem o Rio Grande de São Pedro, tal perda significaria "huá porta aberta e franca dentro da nossa casa" ${ }^{74}$.

Nesse tenso quadro geopolítico, a estratégia militar a ser adotada era a de direcionar todas as forças da Capitania de São Paulo, bem como de todas as demais, aos lugares em que fossem de maior importância. Assim, "A conservação do R. ${ }^{\circ}$ Grd..$^{\mathrm{e}}$ hé indisputavel ser ella a mais importante ${ }^{\mathrm{a}}{ }^{\mathrm{a}}$ a conservação da Cap. ${ }^{\text {nia }}$ de V.E. ${ }^{a}$, e athe p. ${ }^{a}$ as Capi. ${ }^{\text {nias }}$ de Minas: Senhores os Cast. ${ }^{\text {os }}$ daq. ${ }^{\text {le }}$ Cont. ${ }^{\mathrm{e}}$, ficão cum huá porta aberta e franca dentro da nossa casa, por donde poderão com $m$. $^{\text {ta }}$ facilid. ${ }^{\text {e }}$ fazer-nos huá ruina, q' deficultozam. te possamos reparar" ${ }^{\text {" } 75}$. Ao remeteremse as forças distintivas e características de que dispunha a Capitania de São Paulo para as batalhas então travadas contra os espanhóis, o Marquês manifestava confiança e otimismo com relação a esses combatentes que, historicamente, aterrorizavam os espanhóis: “As forças q' os Cast. ${ }^{\text {os }}$ ali podem ter, são huás forças q' não podem fazer receio aos paulistas. Estes são aq. ${ }^{\text {eles }}$ q' destruírão em todo o tp. ${ }^{\circ}$ aq. ${ }^{\text {la }}$ gente ${ }^{\text {"76 }}$. Reafirmando sua atitude franca e abertamente otimista para com o desempenho dos paulistas, não esquece, entretanto, de afiançar as recompensas de apresamento que adviriam das vitoriosas batalhas, "ficando p. ${ }^{\text {a }}$ elles tudo q. puderem apanhar e ganharem aos mesmos inimigos" $"$ ".

A despeito do fato de este tipo de tropa, composta de caçadores e aventureiros, se configurar, segundo a Coroa, "como parte a mais essencial" forças da Capitania de São Paulo, devia-se tomar em relevante consideração,

\footnotetext{
73 “Carta do Marquês do Lavradio para Martim Lopez Lobo de Saldanha, RJ, 11/4/1777”, BNL, Reservado, Códice 10631.

${ }^{74}$ Idem.

${ }^{75}$ Idem.

${ }^{76}$ Idem.

${ }^{77}$ Idem.

78 “Martinho de Mello e Castro para Dom Luiz Antonio de Souza Mourão, Palácio da Ajuda, 22/4/1774” AHU, Códice 569, p.70.
} 
ainda, a derrota sofrida pelos portugueses, em 3 de junho de 1777, com a tomada, pelos espanhóis, da Colônia do Sacramento. Tal flagrante insucesso representava, portanto, a urgente e inegável necessidade de tornar os componentes daquele contingente militar mais ofensivos, isto é, melhor equipados e municiados, a fim de terem condições de, pelo menos, tentar impedir a expansão do inimigo. Pode-se verificar, entretanto, a condição dessa tropa, quando, em 20 de junho de 1777, o Vice-Rei Marquês do Lavradio, ao responder às solicitações de armas e de fardamento para a tropa de caçadores, feitas por Lopez Lobo, evidencia não só a precária, senão trágica, situação militar em que se encontrava a Capitania do Rio de Janeiro, mas, também, a de como iam esses soldados-caçadores para o fronte de batalha: "V.Ex' me pede armas p. ${ }^{a}$ estes corpos, eu as mandaria a V.Exa se as tivesse, porem eu me acho na mesma

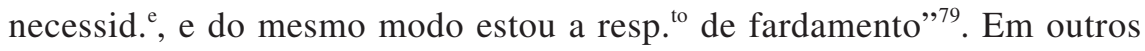
termos, caminhavam para a guerra virtualmente desnudos, sem armamento, "sem camiza e descalços" $"$, e em sua grande maioria, sob forte pressão dos governadores de São Paulo.

De tal vasto relato se conclui que, no perigoso confronto travado com os espanhóis, que, imbatíveis, rendiam as forças portuguesas e conquistavam seus territórios, a tropa constituída de caçadores dispunha, como seu único recurso marcial, da "liberdade p. ${ }^{\text {a }}$ que elles busquem a destruição daq. ${ }^{\text {les }}$ homens por todos os modos q' elles poderem" ${ }^{\prime 81}$. E, inserindo-se tal situação de precariedade no quadro geral das forças e dos armamentos de que, parcamente, dispunham, então, os portugueses nos territórios meridionais a serem defendidos, tornavase a mesma nada menos que alarmante.

Por outro lado, considerando-se a expedição de Cevallos, “jamais se fez um armamento igual para a América" $"$. A despeito de os documentos existentes

\footnotetext{
79 “Carta do Marquês do Lavradio para Martim Lopez Lobo de Saldanha, RJ, 20/6/1777”, BNL, Reservado, Códice 10631

80 “Carta do Marquês do Lavradio para Martim Lopez Lobo de Saldanha, RJ, 1/8/1777”, BNL, Reservados, Códice 10631

81 “Carta do Marquês do Lavradio para Martim Lopez Lobo de Saldanha, RJ, 11/4/1777”, BNL, Reservado, Códice 10631

82 “Intimação de Cevallos ao marquês de Casa Tilly. Bordo do navio Poderoso, 7/2/1777', Campaña del Brasil, 1941, t.3, p.455, Apud, GOLIN, Tau. A Guerra Guaranítica, Op.cit., p.105.
} 
revelarem algumas contradições entre o planejamento da expedição e o número de embarcações e homens para ali dirigidos, as forças e armamentos de que, então, o mesmo dispunha, segundo Tau Golin ${ }^{83}$, só vêm a comprovar a inegável dimensão expedicionária espanhola enviada àquela parcela do Novo Mundo.

Dessa forma, neste embate de tão grande vulto e diante de tão poderosas forças enviadas pelos espanhóis para a (re-)conquista dos territórios meridionais então sob o domínio português, não parecia haver qualquer possibilidade da tropa de aventureiros-paulistas virem a se constituir em elementos significantes, quer quantitativa quer qualitativamente, mesmo em se considerando sua tão afamada "quallidade de ataques e estratagemas com q' ofendem o inimigo, e por isso se fazem m. to $^{\text {temidos" }}{ }^{\text {" } 84}$. Tampouco os armamentos de que dispunham os portugueses, ainda que em quantidade significativa, porém ultrapassados e danificados, tornavam-nos combativos em um embate para o qual os espanhóis se apresentavam tão fortemente equipados. Pode-se, portanto, definitivamente concluir que o principal fator detentor da expedição de Cevallos, foram as negociações de paz estabelecidas entre as Coroas de Portugal e Espanha e seladas no Tratado de Santo Idelfonso, de 1 de outubro de 1777.

Assim, veja que, se por um lado, a Coroa reconhecia a absoluta necessidade e importância de regularização das tropas coloniais para que estas pudessem estar à altura de um afrontamento militar contra as forças adversárias de Espanha, por outro, os armamentos necessários, vindos da Metrópole, dos quais a Colônia dependia totalmente para seu abastecimento, eram parcamente enviados. Nesse contexto de precariedade, bem como da urgência bélica que se fazia na zona meridional da América, tornou-se estrategicamente indispensável o aproveitamento das estratégias locais dos soldados-aventureiros da Capitania de São Paulo. Entretanto, qual poderia ser o resultado militar mesmo de tropas idealmente bem reguladas e submetidas a uma mesma impecável ordem e disciplina, se não estivessem seus combatentes devidamente armados e treinados? De tal carência padecerão as tropas coloniais durante toda a segunda metade do século XVIII.

\footnotetext{
${ }^{83}$ GOLIN, Tau. Op.cit., p.103.

84 “Oficio de Morgado de Mateus para o Conde de Oeiras, S.P., 4/8/1765”, AHU, SP., Avulsos, Cx. 23, doc. 2239.
} 